\title{
Implementasi Aplikasi Service Menggunakan Framework CI Pada PT XYZ
}

\author{
Arfan Sansprayada $^{1)}$, Kartika Mariskhana $^{2)}{ }^{*}$, Riva Abdilah Aziz ${ }^{3)}$ \\ ${ }^{12)}$ Universitas Bina Sarana Informatika \\ ${ }^{3}$ Sekolah Tinggi Manajemen Informatika dan Komputer Nusa Mandiri \\ Correspondence Author: arfan.anp@bsi.ac.id, Jakarta, Indonesia
}

DOI: https://doi.org/10.37012/jtik.v7i2.623

\begin{abstract}
Abstrak
Teknologi merupakan salah satu aspek yang wajib diperhatikan dalam perusahaan agar roda bisnis perusahaan dapat berjalan dengan baik. Terutama perusahaan yang menyediakan layanan jasa ataupun perusahaan yang menyediakan layanan jual beli produk. Pada perusahaan dibidang jasa, hal yang terbaik harus diperhatikan berkaitan dengan pelayanan kepada pelanggan, hal ini yang menjadi perhatian management perusahaan khususnya dalam mengatur waktu mulai dari antrian pelanggan, problem solving dalam tiap permasalahan yang ada serta cepatnya waktu pengerjaan dari sisi karyawan dalam melayani pelanggan. Hal inilah yang mesti diperhatikan bagi perusahaan khususnya dalam perusahaan jasa agar roda bisnis perusahaan dapat berjalan dengan baik. PT XYZ merupakan salah satu perusahaan yang menyediakan jasa perbaikan elektronik dimana dalam perusahaan tersebut masih minimnya implementasi aplikasi yang dapat menyebabkan kurangnya profit perusahaan karena banyaknya waktu tunggu yang terlalu lama bagi pelanggan. Waktu tunggu terlalu lama bagi pelanggan atau konsumen adalah suatu permasalahan yang tidak bisa dianggap remeh, pemberian pelayanan jasa terbaik kepada konsumen adalah salah satu cara untuk mendapatkan kepuasan kepada pelanggan. Banyaknya permintaan konsumen terhadap perbaikan jasa service ini mau tidak mau bagi internal perusahaan harus memberikan suatu sistem informasi dalam bentuk implementasi aplikasi agar setiap divisi dapat terintegrasi secara baik dan benar sehingga kebutuhan dan pelayanan terhadap konsumen dapat dipenuhi dengan baik tanpa ada kendala sedikitpun. Dengan diterapkannya implementasi ini, diharapkan dapat memberikan kemudahan dan kenyamanan khususnya kepada karyawan terutama dalam menjalankan aktifitas nya sehari sehari. Sedangkan untuk perusahaan dapat memberikan profit yang sebesar besarnya dengan pelayanan yang terbaik bagi perusahaan dan memberikan kenyamanan dan pelayanan yang cepat dan tepat kepada pelanggan.
\end{abstract}

Kata Kunci: Implementasi, Teknologi, CI

\begin{abstract}
Technology is one aspect that must be considered in the company so that the company's business wheels can run well. Especially companies that provide services or companies that provide product buying and selling services. In companies in the service sector, the best thing to pay attention to is related to service to customers, this is the concern of company management, especially in managing the time starting from the customer queue, problem solving in each existing problem and the fast processing time from the employee side in serving customers. This is something that must be considered for companies, especially in service companies so that the company's business wheels can run well. PT XYZ is one of the companies that provides electronic repair services in which the company still lacks application implementation which can lead to a lack of company profits due to the long waiting time for customers. Waiting time is too long for customers or consumers is a problem that cannot be underestimated, providing the best service to consumers is one way to get customer satisfaction. The number of consumer requests for service improvement is inevitably for internal companies must provide an information system in the form of application implementation so that each division can be integrated properly and correctly so that the needs and services to consumers can be met properly without any obstacles at all. With the implementation of this implementation, it is expected to provide convenience and comfort, especially to employees, especially in carrying out their daily activities. As for the company, it can provide the maximum profit with the best service for the company and provide convenience and fast and precise service to customers.
\end{abstract}

Keywords: Information Systems, Wedding Packages, Web 


\section{PENDAHULUAN}

Dengan persaingan yang semakin terbuka dan setiap perusahaan harus mempunyai ide yang kreatif khususnya dibidang jasa adalah syarat mutlak untuk memberikan pelayanan yang terbaik kepada pelanggan secara maksimal. Pelayanan terbaik dapat memberikan dampak yang sangat positif bagi perusahaan yaitu dengan mendapatkan pelayanan terbaik maka pelanggan akan percaya kepada perusahaan tersebut. Dengan demikian akan mendapatkan profit bagi perusahaan.

Pelayanan terbaik tidak mudah untuk diciptakan begitu saja, harus adanya implementasi sistem informasi secara terintegrasi dengan baik dan benar ke semua divisi. Dengan harapan bila terciptanya integrasi sistem informasi dengan baik maka akan memudahkan seluruh karyawan dalam mengerjakan peran dan fungsinya masing masing sehingga memberikan pelayanan yang terbaik untuk pelanggan.

Perusahaan ini sudah berdiri sejak tahun 2007, didirikan oleh Alm. Bapak Suyamto yang sampai sekarang masih berkembang bergerak di bidang pelayanan. Kendala atau permasalahan yang sering terjadi di perusahaan yaitu prosedur pelayanan belum terkomputerisasi dengan baik artinya tidak ada track record yang baik secara dokumentasi database customer dan pernasalahan yang dialami customer secara sistematis, report dengan secara baik selama perusahaan ini berdiri, standart operasional pelaksanaan kerja masih belum rapi dan teratur, pendataan barang sering tidak sesuai baik dari sisi purchasing sampai kebagian teknisi atau customer service yang mengecek ada atau tidaknya ketersediaan barang, sehingga pelayanan kepada konsumen masih belum maksimal dikarenakan pengecekan stok barang terlebih dahulu apabila konsumen mempunyai permasalahan teknis dimana permasalahan tersebut mengharuskan untuk mengganti part/bagian pada perangkat tersebut, serta sering terjadi kesalahaan antara admin dan teknisi karna ketidakcocokan data servis dan data pelanggan.

\section{METODE PENELITIAN}

Dalam penelitian ini menggunaakan konsep metode waterfall dalam perangkat lunaknya dan dalam teknik pengumpulan data tugas ini menggunakan beberapa teknik yaitu :

\section{A. Observasi}

Penulis melakukan obervasi ke PT. XYZ, dalam proses observasi ini penulis melakukan pengamatan secara langsung untuk melihat dan memahami kebutuhan sistem yang diperlukan oleh PT. XYZ.

\section{B. Interview}

Setelah penulis memahami permasalahan yang ada pada PT. XYZ, maka untuk lebih mendalami permasalahan yang ada maka penulis melakukan interview kepada para karyawan yang berinteraksi langsung terhadap proses pelayanan yang dibutuhkan apa saja dan membutuhkan fitur fitur apa saja yang dibutuhkan pada perusahaan tersebut terutama fitur service.

\section{Studi Pustaka}

Dalam penelitian ini penulis melakukan studi pustaka yang dilakukan dengan mengumpulkan data-data yang berhubungan dengan pembuatan sistem berbasiskan android dari buku-buku. Selain dari buku-buku, penulis juga mengumpulkan data-data yang berhubungan dengan sistem informasi dan teknologi android dari internet. 


\section{Model Pengembangan Sistem}

Dalam model pengembangan sistem penelitian ini digunakan beberapa model yaitu :

\section{A. Analisa Kebutuhan Sistem}

Dalam tahap ini, melakukan proses analisis kebutuhan yang akan diterapkan dalam PT XYZ yang dibutuhkan kurang lebih aplikasi kebutuhan pelayanan atau service.

\section{B. Desain}

Tampilan antar muka yang didesain nanti terdiri dari beberapa menu dalam fitur yang digunakan. Diantaranya terdiri dari menu fitur login, data servis, teknisi, data laporan dan masih banyak lagi fitur yang akan disajikan.

\section{Code Generation}

Bahasa pemrograman yang digunakan disini menggunakan PHP murni dengan ditambahkan framework CI agar tampilannya lebih user friendly.

\section{Testing}

Pengujian sistem service berbasis CI ini akan dilakukan dengan 2 tahap, pada tahap pertama akan diuji dengan menggunakan metode pengujian white box dimana sebagian tahap pengujian ini meliputi pengujian algoritma yang dibuat, baik pengujian secara sebagian ataupun secara keseluruhan. Dan yang kedua adalah melalui pengujian black box yaitu dengan cara memasukan input pada sistem informasi tersebut, dan hasilnya akan dianalisa apakah sudah sesuai dengan yang diharapkan atau belum.

\section{E. Support}

Implementasi aplikasi service menggunakan CI ini dibangun dengan menggunakan Bahasa pemrograman PHP serta pendukung lainnya.

\section{HASIL DAN PEMBAHASAN}

\section{Analisa Kebutuhan Software}

Mengidentifikasi kebutuhan fungsional perancangan system web dengan penggambaran Entity Relationship Diagram yang terkait.

\section{A. Kebutuhan Pengguna}

Kebutuhan yang didasarkan pada hal hal yang dibutuhkan oleh pengguna terhadap sistem yang akan dibuat. Dalam hal ini terdapat 3 penggunaan yaitu kebutuhan admin, karyawan, teknisi . Berikut penjelasan kebutuhan dari masing-masing pengguna sistem:

1. Kebutuhan Administrator

A1. Adanya from login digunakan untuk keamanan masuk ruang administrator sistem web.

A2. Adanya form data user digunakan untuk mengelola, melihat update status dan menghapus data user.

A3. Adanya form data data servis digunakan untuk melihat dan menghapus data servis. A4. Adanya form pelanggan digunakan untuk meng-input pendapat pelanggan kami.

A5. Adanya form teknisi digunakan untuk menginput data servis yang sudah selesai servis.

A6. Adanya form data complain untuk pelanggan digunakan untuk complain data servis. A7. Adanya form data laporan digunakan untuk melihat semua laporan.

2. Kebutuhan Customer Servis

B1. Adanya form login untuk keamanan dan masuk ke ruang sistem Customer Servis

B2. Adanya profil Customer Servis untuk melihat data user login siapa yang di pakai

B3. Adanya form pelanggan untuk menambahkan pelanggan, melihat data pelanggan maupun menghapus data pelanggan.

B4. Adanya form data services untuk menambahkan data services, melihat data pelanggan maupun menghapus data servis. Dalam form ini adanya form buat harga 
service dan step di mana memberitahukan data service pelanngan sudah selesai atau masih dalam pengerjaan.

B5. Adanya form part masuk untuk menambahkan data barang masuk yang datang dari supplier.

B6. Adanya form proses transaksi service maupun transaksi penjualan barang.

B7. Adanya form laporan data service, costomer service bisa melihat laporan service computer dan printer dan melihat detail service.

B8. Adanya proses penjualan, data bisa di lihat, view dan print data per-record.

3. Kebutuhan Manager

C1. Adanya form login manager untuk keamanan dari sistem kami

C2. Adanya form laporan part masuk hanya melihat laporan semua data tersebut

C3. Adanya form data user hanya melihat laporan semua data tersebut.

C4. Adanya form data supplier hanya melihat laporan semua data tersebut.

C5. Adanya form data pelanggan hanya melihat laporan semua data tersebut.

C6. Adanya form data service hanya melihat laporan semua data tersebut.

C7. Ada form data part hanya melihat laporan semua data tersebut.

C8. Adanya form penjualan hanya melihat laporan semua data tersebut.

\section{B. Kebutuhan Sistem}

Kebutuhan yang didasarkan pada hal hal yang dibutuhkan oleh sistem terhadap user yang akan proses. Dalam hal ini terdapat 3 penggunaan yaitu kebutuhan admin, karyawan, teknisi. Berikut penjelasan kebutuhan dari masing-masing pengguna sistem:

a. Admin harus melakukan login terlebih dahulu untuk dapat mengakses aplikasi ini dengan memasukan username, password dan level user agar privasi masing-masing pengguna tetap terjaga keamanannya.

b. Admin bisa melakukan penghapusan data semua record karna hak akses.

c. Admin harus melakukan Logout setelah selesai mengelola halaman admin.

d. Costomer service harus melakukan login terlebih dahulu untuk dapat mengakses aplikasi

e. Costomer service bisa menambahkan data pelanggan, dan menghapus data pelanggan

f. Costomer service menambahkan data service, mengolah biaya dan step apakah data service sudah selesai atau belum.

g. Costomer service bisa melihat data laporan penjualan dan laporan service maupun print out data tersebut

h. Costomer service harus logout ketika sudah selesai akan aplikasi tersebut

i. Manager harus login terlebih dahulu karna untuk keamanan sistem kami

j. Manager memonitoring semua transaksi yang ada

k. Manager harus logout ketika sudah selesai akan tugasnya

\section{Use Case Diagram}

Berikut adalah hasil perancangan modeling UML pada diagram usecase :

1. Use Case Diagram Administrator 


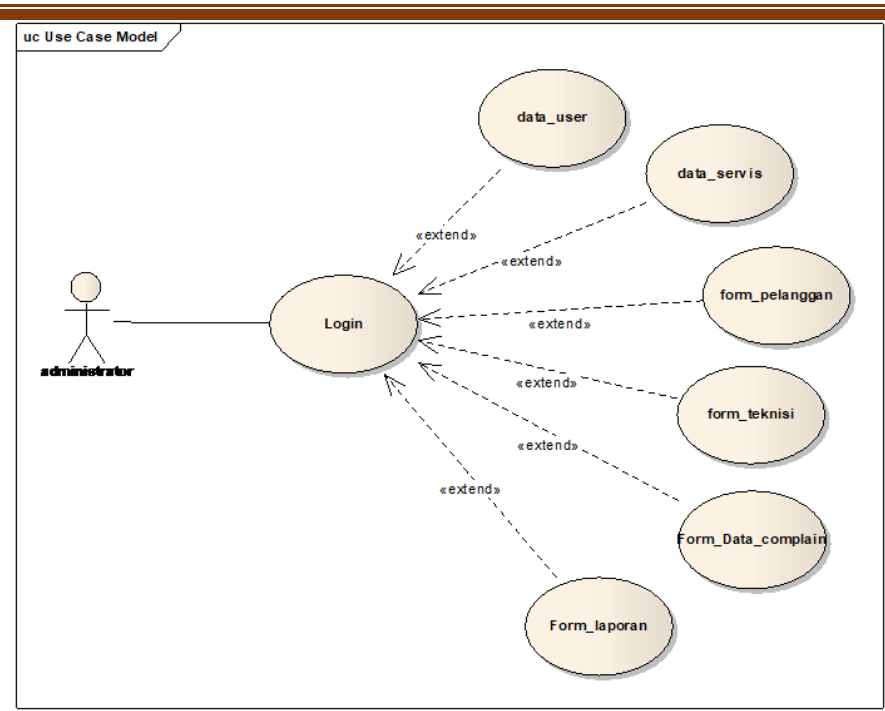

Gambar.1 Use Case Diagram Administrator

Tabel 1. Deskripsi Use Case Diagram Halaman Administrator

\begin{tabular}{ll}
\hline Use Case Name & Mengelola Data \\
\hline Requirement & A1-A7 \\
\hline Pre-Condition & Admin dapat memanage segala kebutuhan semua yang ada \\
pada semua user
\end{tabular}

Invariant

2. Use Case Diagram Customer Service

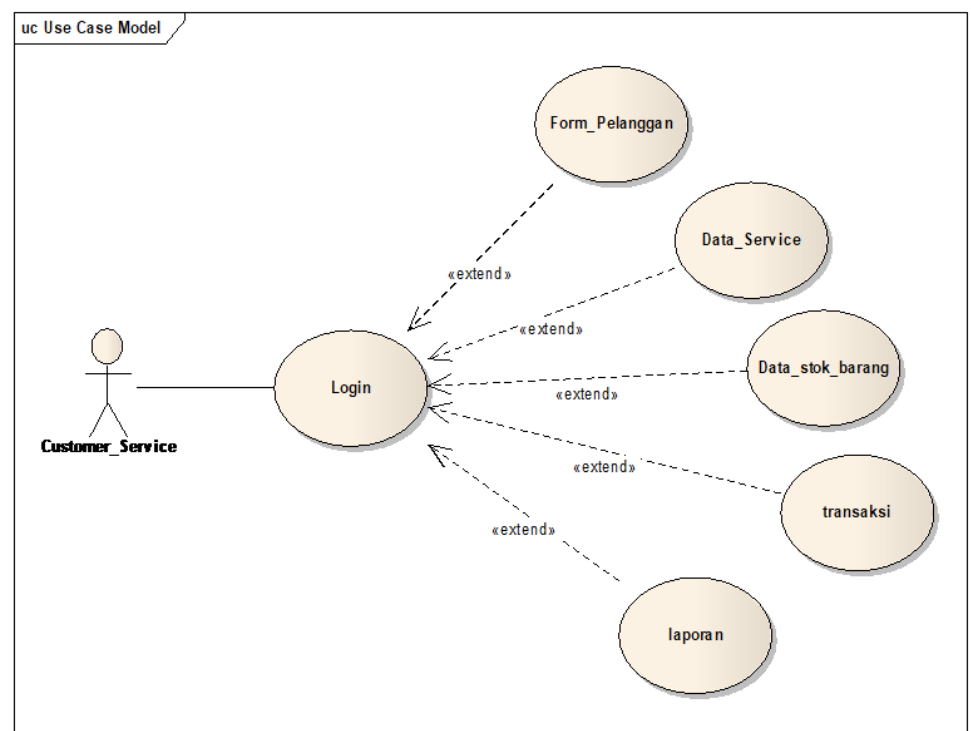

Gambar.2 Use Case Diagram Customer Service 
Tabel 2. Deskripsi Use Case Diagram Customer Service

\begin{tabular}{ll}
\hline Use Case Name & Melakukan input transaksi \\
\hline Requirement & B1-B7 \\
\hline Pre-Condition & Customer service melakukan input transaksi \\
\hline Post Condition & Customer Service telah terdaftar \\
\hline Failed end Condition & Customer Service menginput dan melakukan transaksi \\
\hline Main Flow/ Basic Path & Customer Service dapat menginput dan membatalkan transaksi \\
& 2. Customer Service menginput form pelanggan \\
& 3. Customer Service melakukan data service \\
& 4. Customer Service melakukan pengecekan stok barang \\
\hline
\end{tabular}

Invariant

3. Use Case Diagram Manager

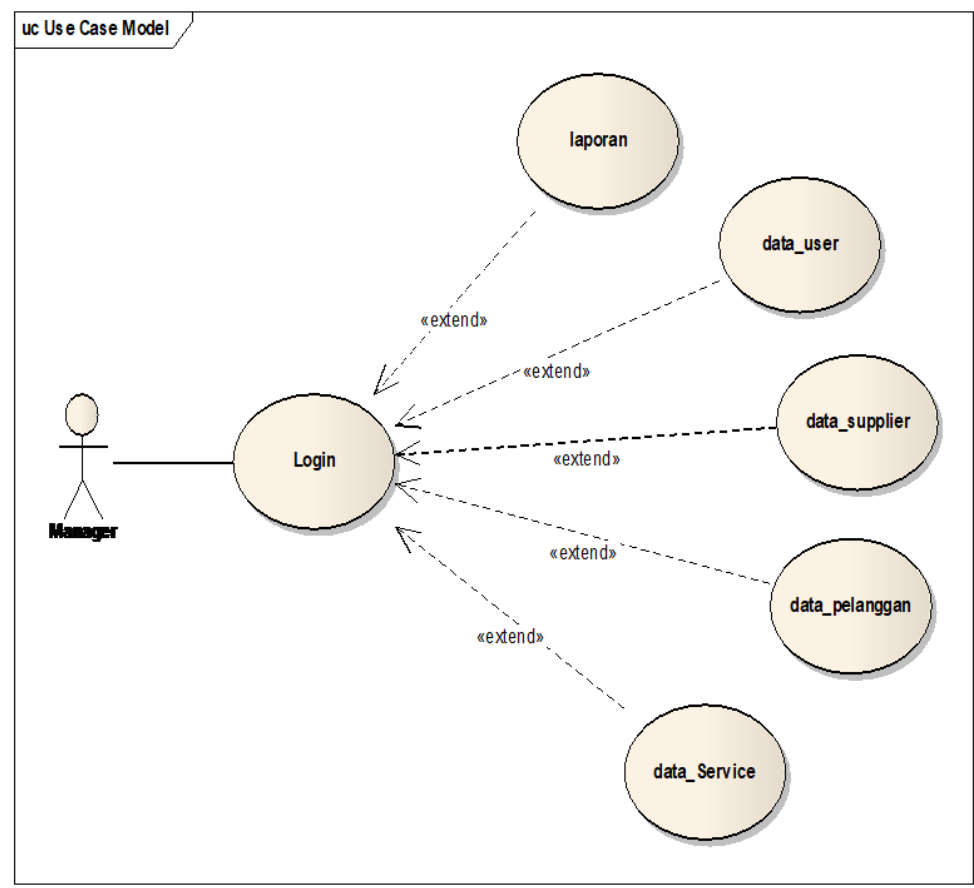

Gambar.3 Use Case Diagram Manager

Tabel 3. Deskripsi Use Case Diagram Manager

\begin{tabular}{ll}
\hline Use Case Name & Memanage transaksi dan pengecekan Laporan \\
\hline Requirement & C1-C7 \\
\hline Pre-Condition & Manager dapat mengecek laporan serta data service \\
\hline Post Condition & Manager telah terdaftar \\
\hline Failed end Condition & Manager dapat menginput dan membatalkan transaksi \\
\hline Main Flow/ Basic Path & 1. Manager dapat melakukan pengecekan laporan \\
& 2. Manager dapat melihat data user \\
& 3. Manager dapat melihat data supplier \\
& 4. Manager dapat melihat data pelanggan \\
& 5. Manager dapat melihat data transaksi/service \\
\hline
\end{tabular}

Invariant 


\section{Activity Diagram}

\section{Activity Diagram Login dan Registrasi Customer}

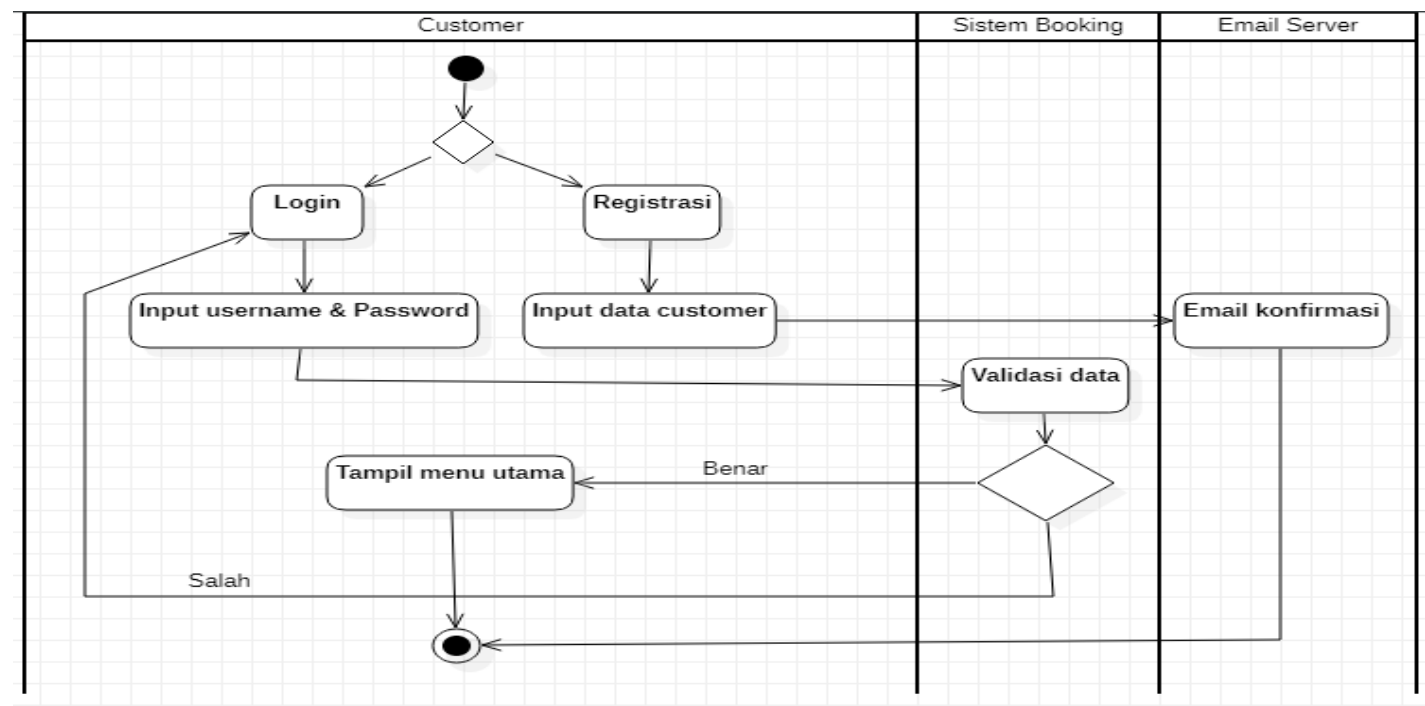

Gambar 4. Activity Diagram Login dan Registrasi

\section{Activity Diagram Customer dan Admin}

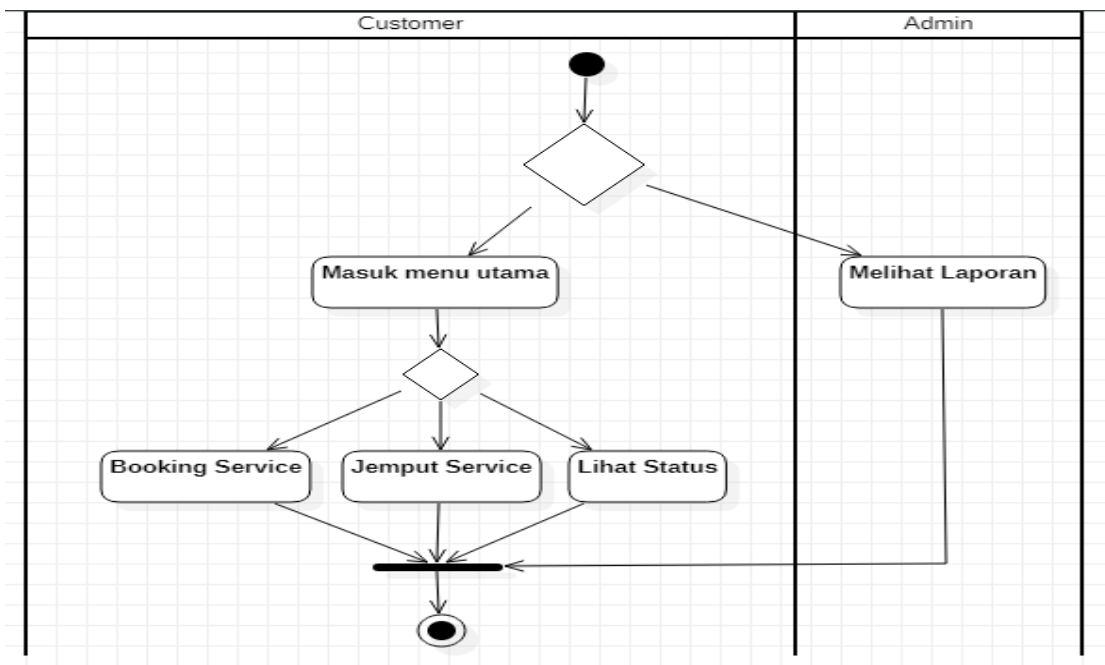

Gambar 5. Activity Diagram Admin dan Customer 


\section{DesainDatabase}

\section{Entity Relationship Diagram}

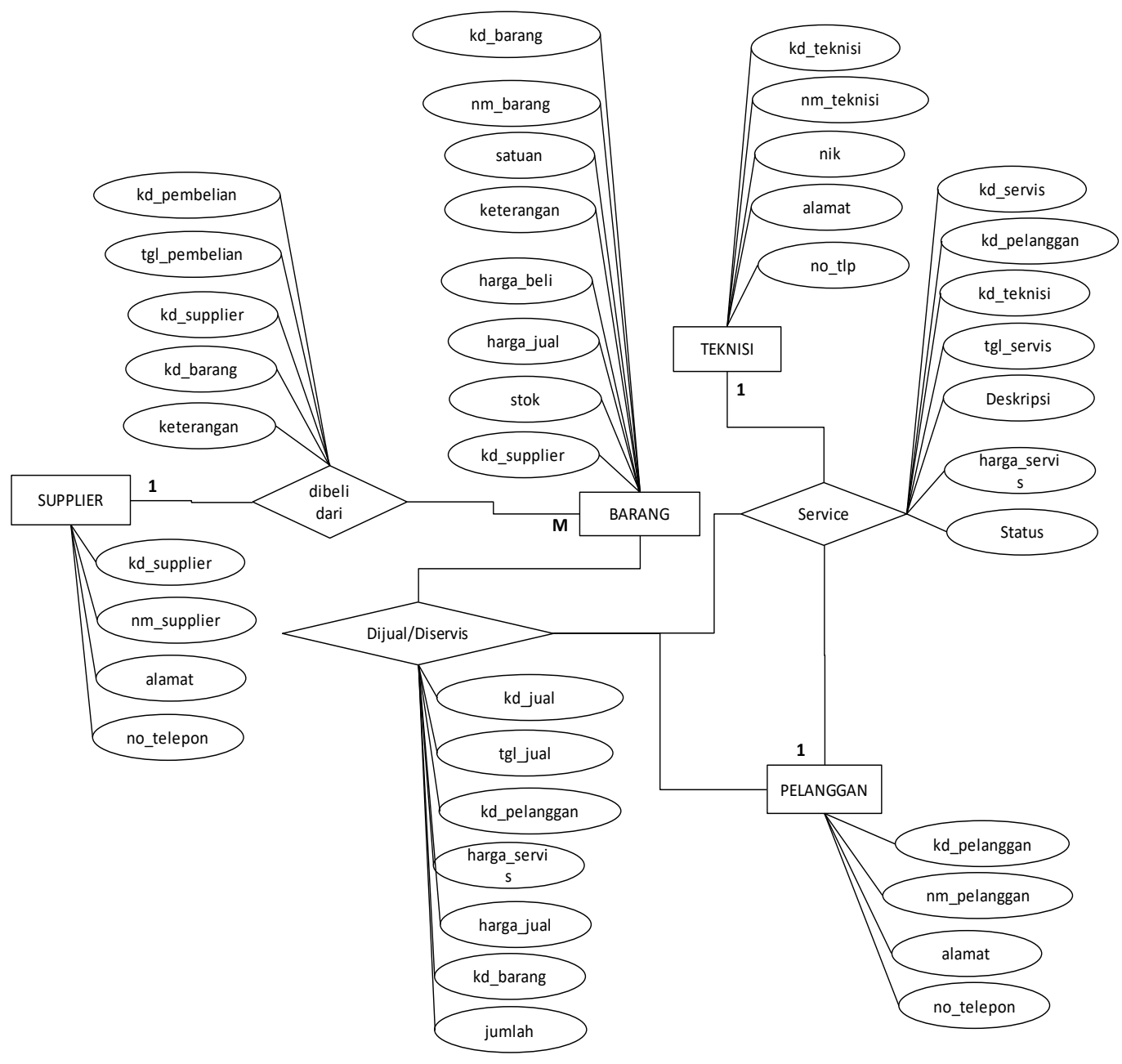

Gambar 6. Entity Relationship Diagram

\section{Logical Record Structure}

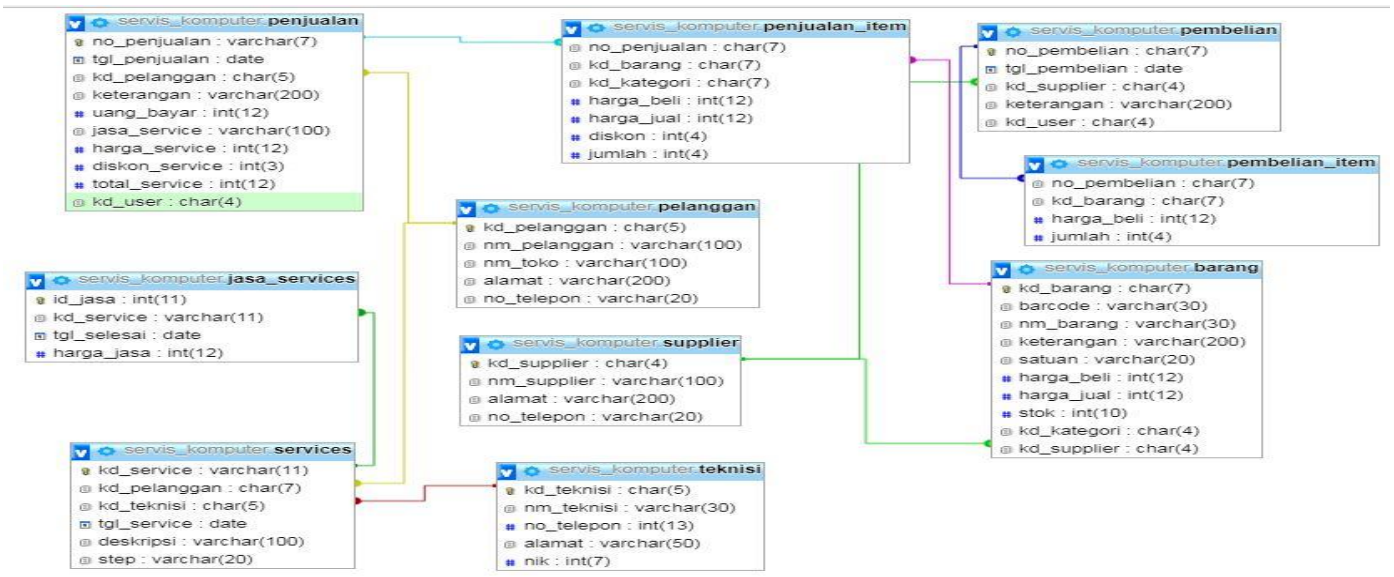

Gambar 7. Logical Record Structure 


\section{User Interface}

1. Halaman login

Administrator, customer service maupun manager harus melakukan login terlebih dahulu untuk dapat menggunakan modul-modul yang tersedia. Jika login berhasil, maka menu-menu yang sesuai kategori user tersebut akan tampil.
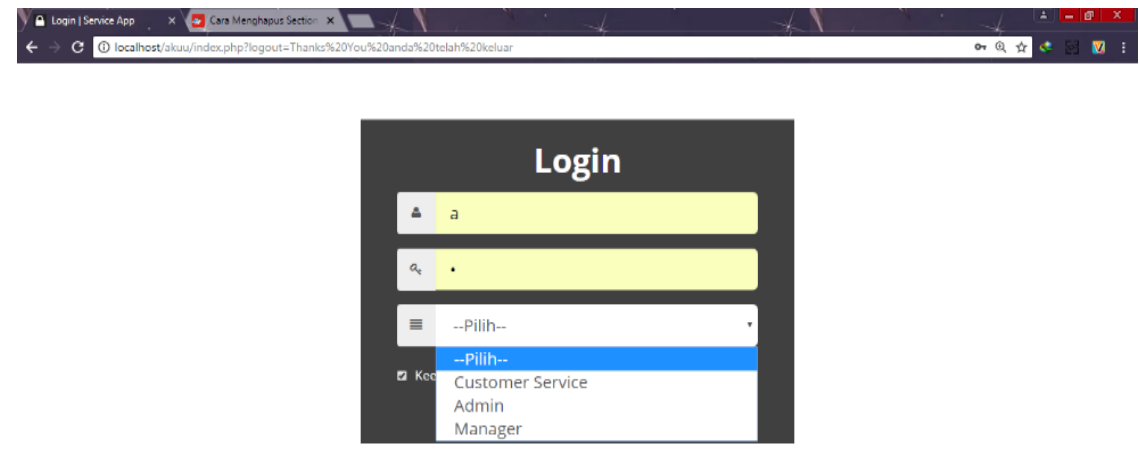

\section{(5) D 9 D

Gambar 8. Halaman Login

2. Halaman Beranda Admin

Administrator dapat menggunakan menu yang tersedia dihalaman admin dengan mengklik salah satu menu sesuai yang diinginkan. Administrator juga dapat menambahkan, meng-edit atau menghapus isi dari website.

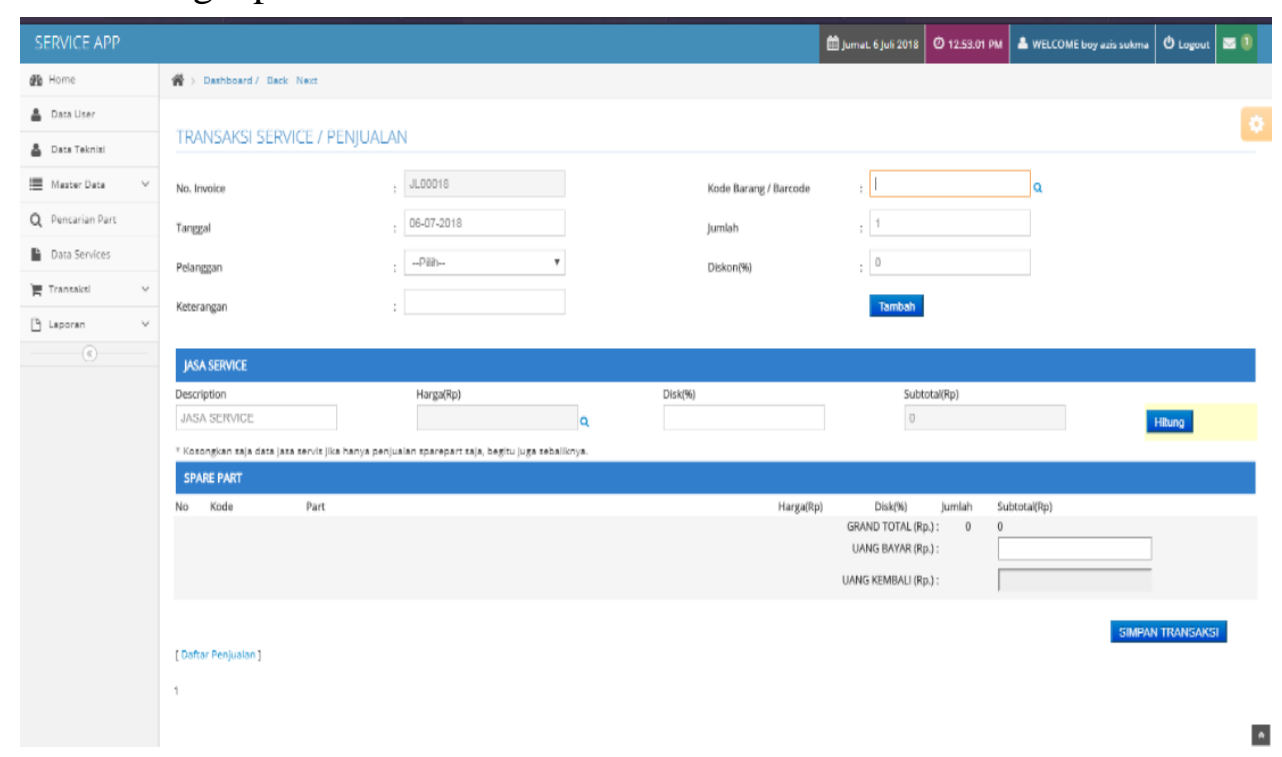

Gambar 9. Halaman Beranda Admin 
3. Halaman Beranda Manager

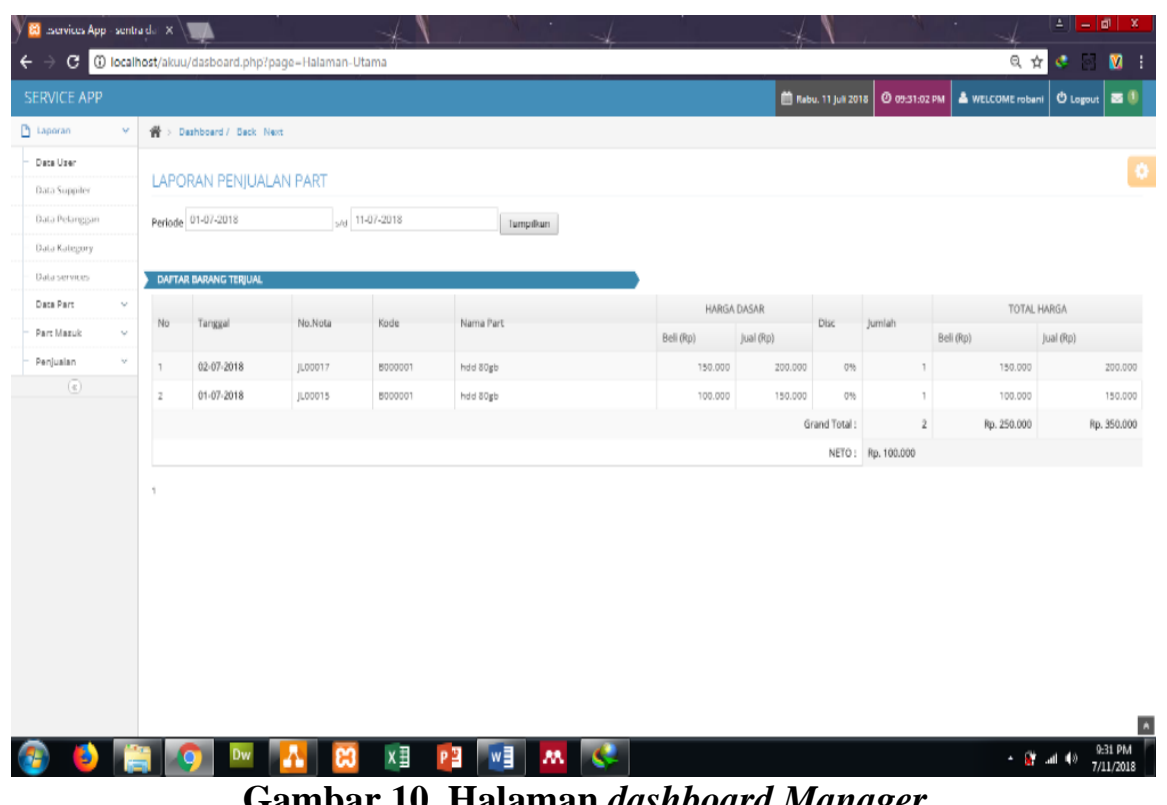

Gambar 10. Halaman dashboard Manager

4. Halaman Beranda Costomer Servis

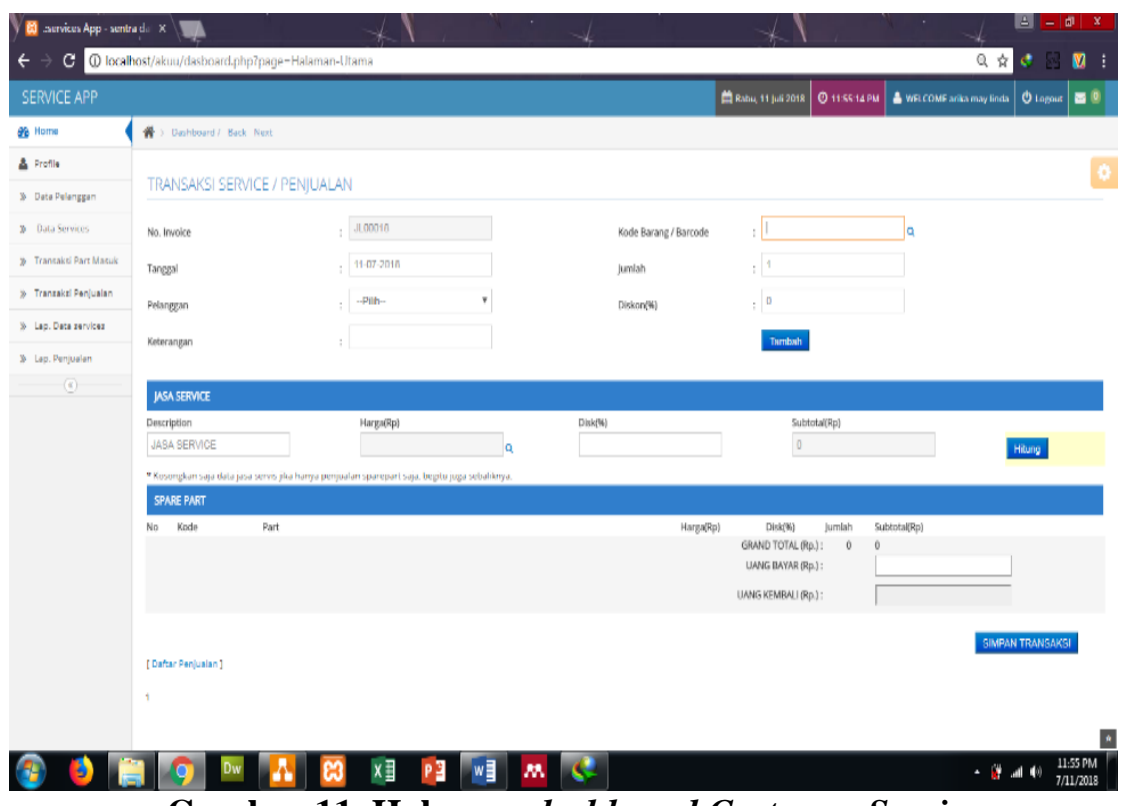

Gambar 11. Halaman dashboard Costomer Servis

\section{KESIMPULAN DAN REKOMENDASI}

Berdasarkan hasil pengembangan dari sistem yang telah penulis lakukan, maka penulis mencoba memberikan suatu kesimpulan dan mengajukan beberapa saran-saran yang berhubungan dengan pembahasan yang telah dikemukakan di bab-bab sebelumnya.

Berikut ini kesimpulan yang dapat penulis ambil yaitu :

1. Dengan adanya implementasi service berbasis CI ini memudahkan dari sisi perusahaan agar lebih cepat dan tepat waktu dalam melayani customer dalam bidang jasa atau perbaikan. 
2. Memberikan data pelanggan yang akurat serta memberikan report data yang baik dan terkomputerisasi dengan baik bila implementasi sistem ini diterapkan.

Sedangkan saran dari hasil penelitian ini adalah :

1. Diharapkan kedepan adanya pengembangan tidak hanya mengimplementasikan dari sistem pelayanan service nya saja tetapi diintegrasikan selayaknya sistem ERP (Enterprise Resource Planning) artinya dapat diintegrasikan ke seluruh divisi agar semua aktivitas tercatat atau terecord dengan baik.

2. Dengan berjalannya implementasi ini diharapkan kedepan juga perlu diadakan maintance system secara periodic atau berkala agar tidak ada kendala atau bug yang memperlambat kinerja system.

\section{REFERENSI}

Anggraeni, E. Y., \& Irviani, R. (2017). Pengantar Sistem Informasi. (E. Risanto, Ed.).Yogyakarta: Penerbit

Agustino, R., Widodo, Y. B., Wiyatno, A., \& Saputro, M. I. (2020). Sistem Informasi Penelitian dan Pengabdian Masyarakat di Universitas Mohammad Husni Thamrin. Jurnal Jaring SainTek, 2(1), 1-12.

Andi.Bakhri, S. (2015). Rancang Bangun Sistem Informasi Penjualan Sembako Menggunakan Metode Waterfall, 3(1), 70-82.

Hery. (2012). Pengantar Akuntansi 1. Jakarta: Fakultas Ekonomi Universitas Indonesia.

Muslihudin, M., \& Oktafianto. (2016). Analisis dan Perancangan Sistem Informasi Menggunakan Model Terstruktur dan UML. (A. Pramesta, Ed.). Yogyakarta: Penerbit Andi. Puspitasari, D. (2015). Rancang Bangun Sistem Informasi Koperasi Simpan Pinjam Karyawan Berbasis Web. Seminar Nasional Ilmu Pengetahuan Dan Teknologi Komputer, XI(2), 186-INF.196.

Rahmawati, M. (2015). Peran Aplikasi Komputer Berbasis Akuntansi untuk Badan Usaha Dalam Persfektif Sistem Informasi, XIII(2), 172-183.

Ramanda, K., Rusman, A., \& Agustin, R. (2017). Rancang Bangun Sistem Informasi Service Center Pada PT . Catur Sukses Internasional Jakarta, 7(2), 1-5.

Sopian, A., Agustino, R., \& Wiyatno, A. (2020). Perancangan Aplikasi Surat Menggunakan Framework Codeigniter Dan Bootstrap Pada LPPM Universitas Mohammad Husni Thamrin. Jurnal Teknologi Informatika dan Komputer, 6(2), 47-62. 